\title{
CLAVES EN LA CONSTRUCCIÓN DEL CONOCIMIENTO DE LA EDUCACIÓN INCLUSIVA
}

\author{
KEYS IN BUILDING KNOWLEDGE OF INCLUSIVE EDUCATION
}

CHAVES NA CONSTRUÇÃO DO CONHECIMENTO DA EDUCAÇÃO INCLUSIVA

\author{
Aldo Ocampo González \\ Centro de Estudios Latinoamericanos de Educación Inclusiva (CELEI) ${ }^{1}$ - Chile
}

\begin{abstract}
Resumen: la teoría de la educación inclusiva al explicitar una naturaleza abierta exige pensar acerca de lo que esta hace en el mudo y cómo resuelve determinados problemas, intentando visualizar sobre qué otras cosas articula su trabajo. La educación inclusiva al no pertenecer con exactitud a la regionalización significada como educación especial, reafirma que sus contornos definitorios han sido establecidos mediante un conjunto de equívocos de aproximación al propio término. El objetivo de este trabajo es analizar algunas de sus premisas heurísticas para comprender sus mecanismos de producción del conocimiento. El método empleado es el de revisión documental crítica. Entre sus principales conclusiones el trabajo identifica que la estructura de conocimiento de lo que denominamos educación inclusiva queda integrada por una diversidad de voces que contribuyen a la comprensión de variados tópicos y vínculos con las diversas estructuras del mundo y sus sistemas, exigiendo la adopción de nuevos métodos para problemas que no logran ser comprendidos bajo el purismo conservador del trabajo metodológico. Los territorios de lo inclusivo construyen una epistemología neo-materialista.
\end{abstract}

Palabras clave: construcción del conocimiento; educación inclusiva; diasporismo; transposiciones; enredos genealógicos; problemas definitorios.

\begin{abstract}
: the theory of inclusive education by making explicit an open nature requires thinking about what it does in the world and how it solves certain problems, trying to visualize on what other things its work articulates. Inclusive education, not belonging exactly to the regionalization signified as special education, reaffirms that its defining contours have been established through a set of misunderstandings of approximation to the term itself. The objective of this work is to analyze some of its heuristic premises to understand its mechanisms of knowledge production. The method used is the critical documentary review. Among its main conclusions, the work identifies that the knowledge structure of what we call inclusive education is made up of a diversity of voices that contribute to the understanding of various topics and links with the various structures of the world and their systems, demanding the adoption of new methods for problems that cannot be understood under the conservative purism of methodological work. The territories of the inclusive construct a neo-materialist epistemology.
\end{abstract}

Key words: knowledge construction; inclusive education; diasporism; transpositions; genealogical entanglements; defining problems.

\footnotetext{
${ }^{1}$ Primer centro de investigación creado en Chile y en América Latina y el Caribe (ALAC), dedicado al estudio teórico y metodológico de la educación inclusiva, articula su trabajo desde una perspectiva inter-, post- y para-disciplinar. Institución internacional reconocida y con estatus afiliativo por el Consejo Latinoamericano de Ciencias Sociales (CLACSO) y por el International Consortium of Critical Theory Programs (ICCTP), EE.UU.
} 
Resumo: a teoria da educação inclusiva, ao tornar explícito um caráter aberto, exige pensar sobre o que faz no mundo e como resolve certos problemas, tentando visualizar em que outras coisas seu trabalho articula. A educação inclusiva, não pertencendo exatamente à regionalização significada como educação especial, reafirma que seus contornos definidores foram estabelecidos por meio de um conjunto de malentendidos de aproximação do próprio termo. O objetivo deste trabalho é analisar algumas de suas premissas heurísticas para compreender seus mecanismos de produção de conhecimento. O método utilizado é a revisão documental crítica. Entre suas principais conclusões, o trabalho identifica que a estrutura de conhecimento do que chamamos de educação inclusiva é constituída por uma diversidade de vozes que contribuem para a compreensão de diversos temas e articulações com as diversas estruturas do mundo e seus sistemas, exigindo a adoção. de novos métodos para problemas que não podem ser compreendidos sob o purismo conservador do trabalho metodológico. Os territórios do inclusivo constroem uma epistemologia neo-materialista.

Palavras-Chave: construção do conhecimento; Educação inclusiva; diasporismo; transposições; complicações genealógicas; definição de problemas.

\section{I.-Introducción}

La teoría de la educación inclusiva al explicitar una naturaleza abierta exige pensar acerca de lo que esta hace en el mudo y cómo resuelve determinados problemas, intentando visualizar sobre qué otras cosas articula su trabajo; todos ellos, mecanismos interesantes para correr el marco y contribuir a la emergencia de otros puntos de vista y amplitud del fenómeno. Nos enfrentamos así, a una práctica imaginativa que abre el abanico de problemas y tópicos de trabajo a un devenir-otro. Si la educación inclusiva es un punto de partida de los procesos de escolarización en el mundo contemporáneo, ¿qué otras cosas moviliza para encuadrar sus tareas? Si la inclusión es el punto de partida en la creación de un proyecto político y de estadonación, queda la pregunta acerca de los agentes de movimiento que fomentan su efecto de diasporización, nomadismo y viaje por diversas geografías intelectuales y proyectos políticos y de conocimiento en resistencia.

La educación inclusiva al no pertenecer con exactitud a la regionalización significada como educación especial, reafirma que sus contornos definitorios han sido establecidos mediante un conjunto de equívocos de aproximación al propio término. La complejidad que supone el rastreo del origen del sintagma, del objeto y del campo devela que no existe un lugar a priori para la inclusión en las estructuras académicas, ni en sus enredos genealógicos, ni en sus comunidades de práctica. Debido a su ambivalencia y fuerza de creatividad será algo que se refina, rearticula, traduce y transforma en su interacción con diversas clases de recursos constructivos que ensamblan sus territorios de trabajo. El tipo de debates, sus instrumentos conceptuales, formas metodológicas y modalidades de teorización comprenden que la inclusión al ser un proyecto de conocimiento en resistencia va más allá de las humanidades, las ciencias sociales, la educación, la filosofía, los estudios de género, la psicología y las ciencias políticas, 
entre otras. Las operatorias del término en el mundo actual explicitan un cambio social complejo y una articulación micropolítica de la teoría.

Uno de mis intereses investigativos ha consistido en explorar aleaciones e interfaces poco convencionales para develar las formas de producción de su conocimiento, empresa que ha consistido en trasladar las categorías de inclusión y de educación inclusiva a territorios desconocidos y poco habituales en el gran campo de intereses de lo educativo. Ninguno de los problemas constitutivos y de trabajo de la inclusión pueden ser capturados en un sentido definitivo y estable, más bien, crea una experiencia de conexión por rearticulación mediante temas alejados que se encuentran muchas veces separados, al encontrarse se rearticulan y germinan hacia otras direcciones. Necesitamos conocer lo qué es la inclusión para saber lo que ha hecho concretamente en el mundo. A pesar que esta se ha centrado mayoritariamente en experiencias de personas en situación de discapacidad -mediante la imposición errónea del modelo epistémico y didáctico de educación especial-y grupos vulnerables, establece que no hay ninguna razón por la que esta no pueda involucrar otras categorías, subjetividades, problemas, sujetos y territorios. La inclusión no se encuentra fija en ninguna posición teórica particular; la teoría puede moverse y se mueve. Es clave para reformular diversas clases de problemas y hacer imaginables nuevas soluciones. Inclusión y educación inclusiva son fenómenos que se construyen mutuamente.

La inclusión a pesar de trabajar para superar diversas clases de desigualdades educativas y sociales, ha sido incapaz de ofrecer respuestas más audaces para comprender la mecánica constitutiva de cada una de estas formas en la diversidad de estructuras del sistema-mundo. Este punto caliente exige asumir sus contornos en términos de enfoque epistemológico, perspectiva metodológica y herramienta de acción e intervención -esta última, apela a la consolidación de un mecanismo de penetración de la realidad para consolidar una pragmática epistemológica de carácter micropolítica-. Otra de sus tareas críticas consiste en aprender a entender los engranajes de funcionamiento y reproducción sistemática de los modelos históricos y emergentes de injusticias, opresión, exclusión y dominación. Interroga los modos de apropiación y consumo de los Otros, invitándonos a salir el pensamiento de oposición sustentado en una gramática binarista de carácter hegeliana.

\section{II.-La educación inclusiva no existe como campo heurístico; no posee teoría ni método/metodologías de investigación solo un conjunto de influencias que viajan por diversas regionalizaciones de estudio}

La teoría es un tema controvertido en la interioridad de los estudios de educación inclusiva. Si la educación inclusiva no posee teoría, ni un ámbito de formalización académica 
refinada, entonces, es legítimo preguntarnos acerca del tipo de teoría que designa. Esta interrogante es parte de una pregunta mayor: el estatus científico del campo. La teoría es una singular forma de producir modos de pensar el mundo y formular entendimientos complejos. La necesidad de teoría no es antojadiza, describe una preocupación mayor: al emerger de un singular espacio diaspórico no aglutina, ni trabaja con objetos teóricos comunes, sino que, con múltiples objetos de diversa naturaleza e incluso desconocida. Una de sus principales obstrucciones puntualiza en el privilegio de conceptos miméticos que ensamblan una función que no le pertenece: sistema de agenciamiento que no logra liberar los problemas de la multiplicidad. Persiste en la gramática del individualismo-esencialismo. El funcionamiento mainstream procede mediante la abducción desmedida, el entrecruzamiento y la contaminación lingüística, estableciendo una falacia referencial en el tratamiento de sus instrumentos conceptuales de mayor alcance, oscureciendo las características y contornos definitorios del campo, objeto y ejes metodológicos. La inclusión y la educación inclusiva asumen un compromiso teórico más amplio con una gran diversidad de problemas del mundo. El objeto, el campo, la teoría y el método de la educación inclusiva operan como espacios de naturaleza viajera, diaspórica e intensamente creativa. "La teoría se define por sus efectos prácticos, como lo que cambia las opiniones de las personas, les hace pensar de manera diferente sobre sus objetos de estudio y sus actividades al estudiarlos" (CULLER, 2009, p.4).

Uno de los problemas de definición que enfrentan los territorios de lo inclusivo no es solo la ausencia de un método y de una teoría, más bien, una impronta sancionada por su propia comunidad de práctica que brinda mayor cabida a la doxa que a planteamientos refinados diluidos en un supuesto efecto de pragmatización. El problema actúa en un peculiar doblete: su arquitectura se compone de diversas clases de enunciación teórica que se disuelven, reclamando una teoría que sea práctica, que penetre la vida de las personas y articule un cambio sustantivo en su realidad. Una teoría de la educación inclusiva sugiere mirar de nuevo las cosas, tener la voluntad de teorizar a su favor para reinventar el mundo conocido y consolidar una pragmática epistemológica de carácter micropolítica. El poder de su discurso ha posicionado a la inclusión a un nivel transnacional, la expansión del alcance se debe en parte a ciertos ámbitos discursivos que dicen relación con diversos tópicos de lucha por la justicia social y la equiparación de oportunidades, sin embargo, no es posible sostener que, tal expansión se deba a la consolidación de una fuerza a nivel de enfoque y posición epistemológica. Una peculiaridad en este proceso de expansión describe que la fuerza del significado profundo del calificativo no emerge desde una fuerza centrífuga derivada del propio territorio, sino que, la consolidación de sus contornos teóricos procede de diversos campos - trayectoria rizomática y enredos genealógicos. La fuerza 
del calificativo es un objeto específico en diversos proyectos políticos contemporáneos y geografías intelectuales, lo que se torna evidente cuando examinamos sus diversos tópicos de análisis y luchas de mayor impacto de algunos de los movimientos sociales críticos y proyectos políticos del mundo contemporáneo; por ejemplo, los derivados del feminismo, el antirracismo, etc.

La carencia de método y teoría, en cierta medida, puede ser explicada por la ausencia de debate interno radical, así como, la falta de principios teóricos fundamentales, lo que en la interioridad del dominio se complejiza aún más a través de su fuerza aléctica y diversal pluralismo. Al develar su naturaleza un conjunto de territorios en permanente movimiento atravesados por diversas clases de categorías, objetos de diversas magnitudes y con caminos multidireccionales, describe su función en términos de un campo de trayectorias rizomáticas cuyas temáticas no se encuentran unificadas por un lenguaje teórico ni un objetivo común. Solo coexiste una actitud intelectual compartida en diversos grados. La educación inclusiva como territorio heurístico de carácter rizomático desafía las modalidades y dependencias jerárquicas ligadas a la producción del conocimiento, plantea una estrategia para producir pluralidades, multiplicidades, sistemas de alteración, etc., fomentando nuevas conexiones, redoblamientos y rearticulaciones, argumentos que proporcionan trayectorias múltiples para pensar sus desarrollos genealógicos y sus fuerzas expansivas, es algo que se disemina a través y más allá de diversas trayectorias intelectuales, éticas y políticas. La fuerza rizomática inaugura un contra-espacio de producción del conocimiento de lo inclusivo compuesto de diversas raíces, una naturaleza aléctica y polifónica; un singular terreno con raíces y hebras enredadas en dimensiones en permanente movimiento y en direcciones desconocidas, una "operación por variación, expansión, conquista, captura, ramificaciones. Además, "el rizoma es alianza, única alianza"” (OPPERMANN, 2010, p.19).

La educación inclusiva no posee teoría, sino un conjunto de influencias que viajan y se movilizan por diversos campos y regionalizaciones intelectuales. En materia de epistemología solo se evidencian los trabajos desarrollados por Ocampo (2017). A continuación, se describen, de manera sintética, algunos de los problemas fundamentales que expresa la educación inclusiva en tanto campo de estudio y dispositivo heurístico.

\section{1-Problemas fundamentales de la educación inclusiva}

Problema ontológico
Este nivel de análisis describe una comprensión restrictiva y normativa devenida en una práctica ininteligible para describir la realidad y al sujeto educativo. Las trayectorias intelectuales de la educación inclusiva describen que este campo ha adoptado y contribuido a clarificar e iluminar las figuraciones ontológicas de los sujetos educativos imponiendo criterios de legibilidad que surgen de la matriz de esencialismos-individualismos, de la empresa ontologizadora del humanismo clásico y de la acción dialéctica hegeliana. 


\begin{tabular}{|c|c|}
\hline $\begin{array}{c}\text { Problema } \\
\text { epistemológico }\end{array}$ & $\begin{array}{l}\text { El problema epistemológico de la educación inclusiva opera a través de un doblete analítico: } \\
\text { por un lado, explícita la ausencia de una construcción teórica propia, así como, una } \\
\text { incomprensión creciente acerca de sus condiciones de producción del conocimiento. Sumado } \\
\text { a ello, las articulaciones y convergencias que definen su base heurística: lo post-disciplinar. }\end{array}$ \\
\hline $\begin{array}{c}\text { Problema } \\
\text { metodológico }\end{array}$ & $\begin{array}{l}\text { Dimensión que describe otro aspecto espinoso en la comprensión del dominio. Esta no } \\
\text { presenta un método y un conjunto de metodologías propias y coherentes con su base } \\
\text { epistemológica para abordar la gran diversidad de fenómenos que conforman sus territorios. } \\
\text { La educación inclusiva al no poseer metodologías de investigación propias, recurre a la } \\
\text { aplicación de las metodologías y métodos convencionales legados por las ciencias sociales. } \\
\text { Coexiste así, un sistema de contaminación y entrecruzamiento metodológico que omite la } \\
\text { pregunta por la emergencia de métodos para comprender su objeto e interactuar con diversas } \\
\text { clases de fenómenos. }\end{array}$ \\
\hline $\begin{array}{c}\text { Problema } \\
\text { morfológico }\end{array}$ & $\begin{array}{l}\text { La dimensión morfológica como problema fundamental de la educación inclusiva, analiza las } \\
\text { formas comprehensivas que efectúan los conceptos que comúnmente se emplean para } \\
\text { ensamblar la función de sus territorios y objetos específicos. Ciertamente, los conceptos que } \\
\text { en su historia intelectual han sido empleados para justificar sus tópicos de tematización, no } \\
\text { responden a los desafíos emergentes introducidos por el centro crítico de la multiplicidad. } \\
\text { Estos, provienen de la trama de esencialismos-individualismos a través del cierre teórico que } \\
\text { efectúan las fuerzas de travestización de lo inclusivo como forma de lo especial. Ninguno de } \\
\text { los conceptos empleados para justificar la fuerza de su objeto y sus tareas analítico- } \\
\text { metodológicas le pertenecen en su globalidad. }\end{array}$ \\
\hline
\end{tabular}

Tabla 1: Problemas fundamentales de la educación inclusiva

Fuente: elaboración propia.

\section{2.-Niveles de sustentación científica de la educación inclusiva}

Cada uno de los niveles que participan de los contornos de delimitación científica de la educación inclusiva, siempre han estado presentes, no del todo bien explicitado, con manifestaciones disímiles e incluso contradictorias. En este apartado intentaré demostrar la concepción errónea en las que cada uno de estos niveles ha incurrido -distorsión de los contornos del campo-, acompañado de un examen acerca de cómo esto debiese ser concebido a la luz de la naturaleza de la educación inclusiva. Cada uno de estos niveles integra las regulaciones de todo paradigma, también conocidos como niveles de sustentación de la actividad científica. Frente a esto, emerge una advertencia crucial, que a su vez, dice relación con la pregunta por el estatus de la educación inclusiva: esta no posee condiciones científicas para ser determinada como enfoque y/o paradigma.

\begin{tabular}{|c|c|c|}
\hline \multirow{3}{*}{$\begin{array}{c}\text { Nivel } \\
\text { ontológico }\end{array}$} & \multicolumn{2}{|c|}{ Comprensión del hombre y de la realidad } \\
\hline & $\begin{array}{l}\text { Cómo se ha abordado el entendimiento } \\
\text { tradicionalmente }\end{array}$ & $\begin{array}{c}\text { Cómo debiese abordarse el } \\
\text { entendimiento según las nuevas } \\
\text { demandas del campo }\end{array}$ \\
\hline & $\begin{array}{l}\text { La pregunta por el nivel o base ontológica de la } \\
\text { educación inclusiva devela un estatus de nulidad o } \\
\text { escaza claridad en la interioridad de los debates del } \\
\text { campo. Si coexiste este efecto turbiedad en cuanto } \\
\text { a los criterios de comprensión del ser, del tiempo y } \\
\text { del espacio, es exclusivamente, producto de la } \\
\text { superposición de la retórica visual proporcionada } \\
\text { por el legado de la educación especial, } \\
\text { estableciendo un anclaje con la matriz de } \\
\text { esencialismos-individualismos de la que proliferan }\end{array}$ & $\begin{array}{l}\text { De acuerdo a la redefinición efectuada } \\
\text { por Ocampo (2017, 2019 y 2020) } \\
\text { respecto de las bases ontológicas de la } \\
\text { educación inclusiva, sus } \\
\text { configuraciones emergen en el marco } \\
\text { de una ontología de lo menor, es decir, } \\
\text { una concepción de ser humano y de } \\
\text { realidad centrada en la revolución } \\
\text { molecular, en la fuerza de las } \\
\text { singularidades múltiples que irrumpen }\end{array}$ \\
\hline
\end{tabular}




\begin{tabular}{|c|c|c|}
\hline & 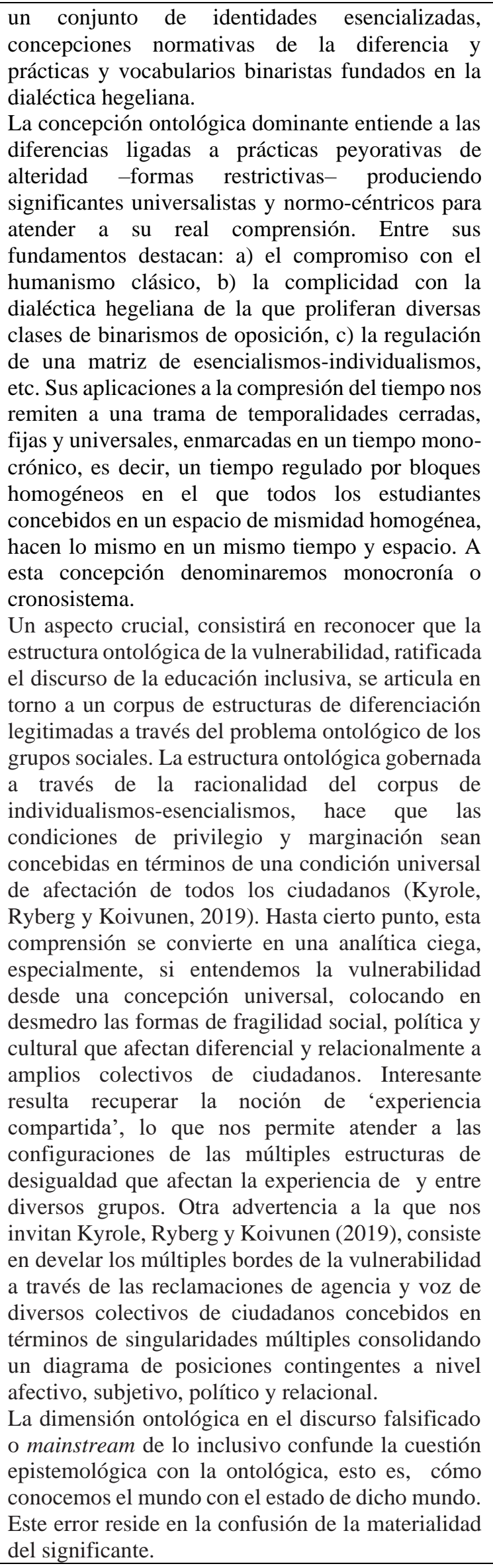 & 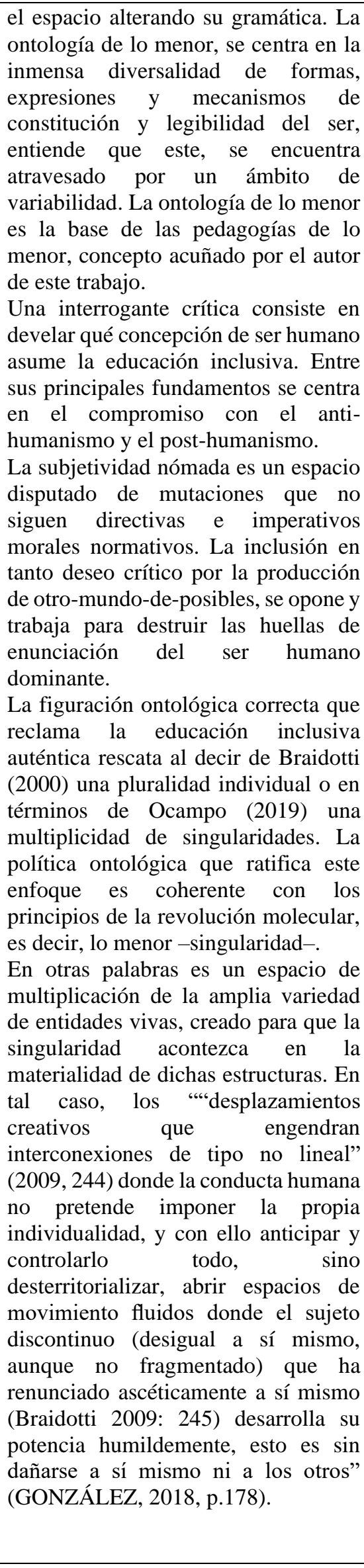 \\
\hline & \multicolumn{2}{|c|}{$\begin{array}{c}\text { Comprensión de la relación investigador/fenómeno, más puntualmente, las formas de } \\
\text { construcción del conocimiento }\end{array}$} \\
\hline
\end{tabular}




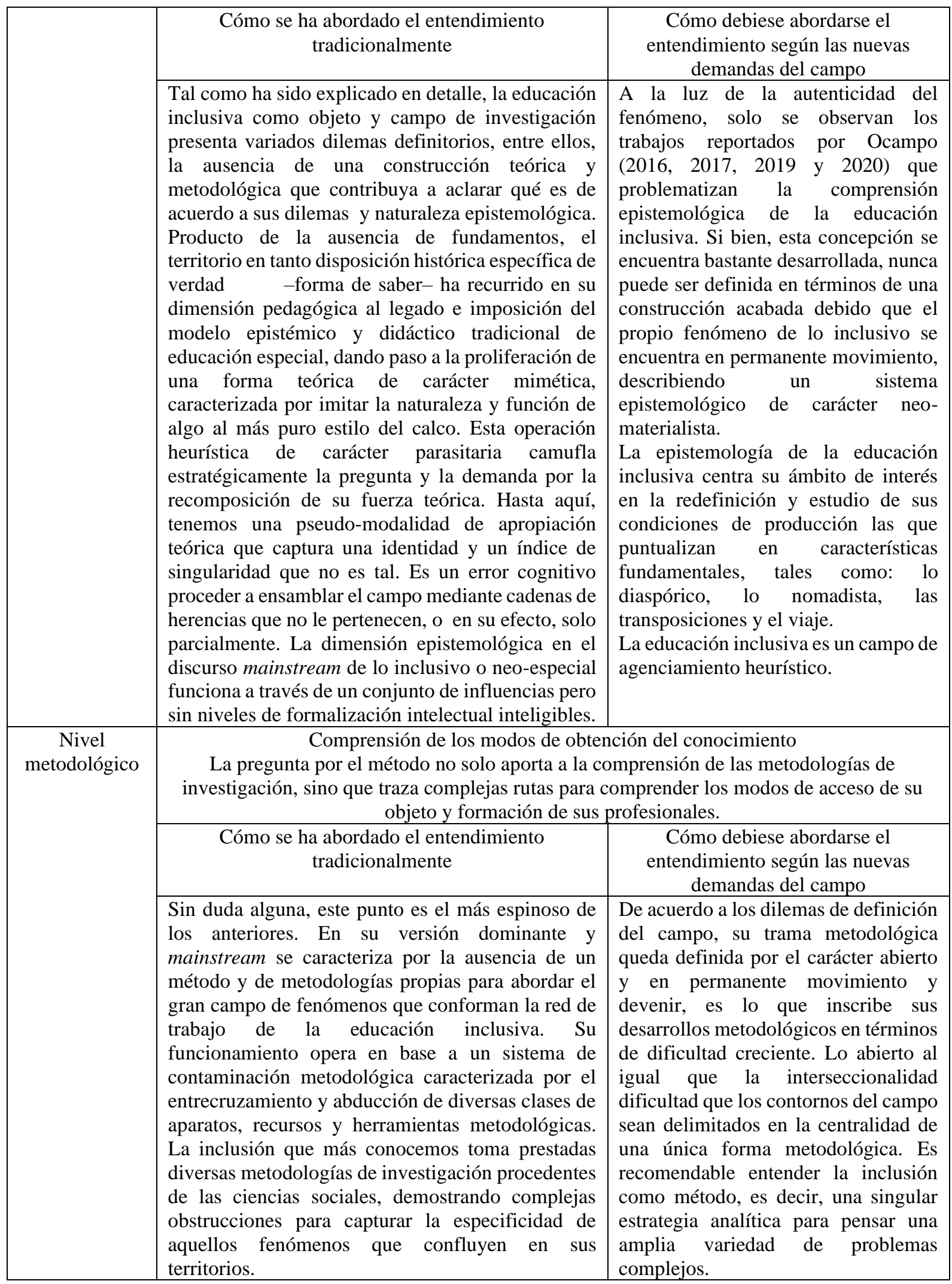

Tabla 2: Síntesis de los niveles de sustentación científica de la educación inclusiva

Fuente: elaboración propia. 


\section{3.-Configuraciones del nivel ontológico en el contexto de una educación inclusiva auténtica}

\begin{tabular}{|c|c|}
\hline $\begin{array}{l}\text { Entendimiento } \\
\text { general }\end{array}$ & $\begin{array}{l}\text { La trama ontológica de la educación inclusiva desde sus demandas de autenticidad, es } \\
\text { decir, comprensión de su identidad e índice de singularidad, desmontada de la fuerza } \\
\text { travestizadora y edipizante de lo especial, plantea otros criterios de legibilidad para } \\
\text { comprender al sujeto educativo desde posiciones ontológicas desconocidas. En el } \\
\text { contexto de una educación inclusiva auténtica, se reconoce la emergencia de una red } \\
\text { ontológica que salta mediante un redoblamiento significativo de figuraciones } \\
\text { esencialistas, sustancialistas e individualistas de carácter liberal hacia un devenir } \\
\text { encarnado y de carácter materialista, asumiendo una política ontológica de lo menor, es } \\
\text { decir, de la fuerza alterativa y disruptiva de la revolución molecular. Esta concepción } \\
\text { de sujeto se centra en la potencialidad de la singularidad; signo y criterio ontológico } \\
\text { que rescata la fuerza de diferencialidad, es decir, los atributos positivos de la persona y } \\
\text { sus fuerzas de potenciación, abandonando una perspectiva centrada en dinámicas de } \\
\text { diferenciación que reproducen el problema ontológico de los grupos sociales. La fuerza } \\
\text { de la singularidad evitar cosificar al sujeto en atributos que delimitan parte de su } \\
\text { identidad en significantes negativos. } \\
\text { La concepción ontológica que ratifica una educación inclusiva auténtica reconoce la } \\
\text { integración de dos conceptos fundamentales en su conceptualización: la multiplicidad } \\
\text { y la singularidad, resultando en el sintagma onto-epistémico y político de singularidades } \\
\text { múltiples, constructo que reconoce las tácticas oblicuas que crean colectivos } \\
\text { significados como minoritarios en tanto formas de existencia y participación en la } \\
\text { interioridad de una estructura homogénea y significada bajo el código absoluto de la } \\
\text { mayoría, alterando su trama de relaciones. La ontología de lo menor es lo que ratifica } \\
\text { una concepción de hombre fundada en las singularidades múltiples, formas de } \\
\text { existencias y subjetividades diversas unas de otras, que escapan y alteran a las formas } \\
\text { de codificación normativas del sujeto educativo. Es una práctica abierta en permanente } \\
\text { devenir. }\end{array}$ \\
\hline $\begin{array}{r}\text { Las config } \\
\text { del tie }\end{array}$ & $\begin{array}{l}\text { Las coordenadas de constitución del tiempo de la educación inclusiva según Ocampo } \\
\text { ( } 2019 \text { y 2020) se estructuran a partir de una concepción de multi-temporalización del } \\
\text { sujeto, lo que es coherente con la heterogeneidad del espacio socio-cultural, pedagógico } \\
\text { y político. Esta concepción parte del reconocimiento que la experiencia del ser en su } \\
\text { forma fenoménica e interactiva se encuentra atravesada a partir de múltiples tiempos, } \\
\text { oponiéndose a la concepción dominante de tiempo monocrónico o tiempo } \\
\text { universal/homogéneo, denominado cronosistema. La concepción del tiempo que } \\
\text { establece la política ontológica de la educación inclusiva auténtica se denomina } \\
\text { heterocronías o múltiples tiempos entrecruzados en un mismo espacio, lo que es } \\
\text { coherente con la premisa de las múltiples singularidades. Esto significa concebir la } \\
\text { totalidad como múltiples singularidades. }\end{array}$ \\
\hline $\begin{array}{c}\text { Las configuraciones } \\
\text { del espacio }\end{array}$ & $\begin{array}{l}\text { Las coordenadas de configuración del espacio actúan de forma interdependiente con las } \\
\text { referidas a la temporalización, ambas formas se co-penetran permanentemente. La } \\
\text { pregunta por el espacio no solo alude a una topología pedagógica, sino que, a las } \\
\text { relaciones simbólicas y subjetivas que en él van configurando la trama de su } \\
\text { materialidad. La concepción de espacio que construye la educación inclusiva auténtica } \\
\text { se funda en la emergencia de un no-lugar, un espacio fuera de serie, un lugar } \\
\text { desconocido. La educación inclusiva desde la perspectiva de Ocampo (2020) inaugura } \\
\text { un nuevo diagrama de posiciones contingentes, situaciones y relaciones que permiten } \\
\text { la configuración de otras coordenadas de alteridad y con ello, dando cabida a las } \\
\text { múltiples expresiones de la singularidad -principio de variabilidad humana-. Se nutre } \\
\text { de los aportes de la geometría del poder impulsada por Massey (1994) para examinar } \\
\text { las configuraciones de las diversas expresiones del poder, tales como, la exclusión, la } \\
\text { segregación, la desigualdad. El espacio que forma la educción inclusiva auténtica es } \\
\text { denominado heterotópico. }\end{array}$ \\
\hline Concepción del ser & $\begin{array}{l}\text { - } \quad \text { Ontología materialista } \\
\text { - } \quad \text { Pedagogía de lo menor } \\
\text { - Criterios de legibilidad que inauguran una nueva forma ontológica y estética -este } \\
\text { último al estilo guattariano- fundada en las singularidades múltiples. }\end{array}$ \\
\hline
\end{tabular}

Tabla 3: Entendimientos generales de la ontología de la educación inclusiva

Fuente: elaboración propia. 


\section{3.-Configuraciones del nivel epistemológico en el contexto de una educación inclusiva auténtica}

Entendimiento general
La educación inclusión auténtica se caracteriza por comprender la naturaleza y autenticidad del fenómeno, lo que en términos heurísticos actúa como sistema de giro, dislocación, redoblamiento de cada uno de los campos y sub-campos constitutivos de la Ciencia Educativa. Una educación inclusiva auténtica es sinónimo de transformación. En este contexto, se convierte en una lucha contra el fracaso y la exclusión, atendiendo al tipo de obstáculos complejos de carácter dinámicos y multinivel que atraviesan la experiencia subjetiva y biográfica de las personas en su paso e interacción por las estructuras de escolarización y de participación y empoderamiento social.

La inclusión se basa en el principio que es la medida de todas las cosas en el mundo contemporáneo. Por tanto, es una compleja praxis, un pensamiento y una filosofía que toma en cuenta todas las necesidades y situaciones de la multiplicidad de singularidades, es una profunda lectura de los signos de nuestro presente. Ambas premisas a nivel teórico crean una síntesis mucho más productiva para pensar los problemas que regulan el mundo que habitamos.

Una concepción más amplia y fina en el estudio de las desigualdades sociales, explícita una conexión entre lo social, la justicia y la solución de las desigualdades sociales complejas -mascaradas-. Favorece un recurso que permite entender que la inclusión, la justicia, los derechos humanos, etc., requieren de herramientas más efectivas para identificar los tipos de distinciones que contribuyen a la discriminación, agrupando las formas de violación de los derechos humanos en varias categorías para conceptualizar la opresión o los frenos al auto-desarrollo.

Este territorio construye un objeto, campo de investigación, una estrategia analítica y una praxis crítica sobre diversas clases de problemas de regulación de las estructuras de los sistemas-mundo contemporáneos. Es un fenómeno propio del agenciamiento heurístico, permite entender nuevos marcos epistemológicos que regulan las definiciones de lo que cuenta como teoría y cómo estas, serán evaluadas. Permite cuestionar las reglas de gubernamentalidad del extrañamiento designado como neoliberal, que no es ni neo ni liberal, es algo mucho más raro.

Fomenta una comprensión de la acción social y los territorios psíquicos de sus implicados -pragmática micropolítica-, clave en las formas avanzadas de grupos subordinados. Es un mecanismo de ruptura con las bases del humanismo y de la gramática del individualismo-esencialismo. Acción social y territorios psíquicos se encuentran al quedar vinculados al contexto social, lo que constituye una forma de fundamentar la teorización dentro de las relaciones de poder, no como una reacción al poder, sino como una acción social en respuesta a las relaciones de poder. Generar un conocimiento resistente superando prácticas informativas y de denuncia sesgadas.

Como metodología opera estableciendo lazos conectivos y anudamientos críticos entre las fuerzas de desarrollo estructural y micropráctico, crea un nuevo diagrama de posiciones contingentes, de relacionamientos y coordenadas de alteridad. La pregunta por los niveles de operación comparte con la interseccionalidad los cuatro niveles del análisis multinivel expuestos por Anthias (1998): a) experiencias, b) prácticas intersubjetivas, c) regímenes institucionales y d) sistemas simbólicos y discursivos. Cada una de estas dimensiones sugieren "aprender a "hacer" un análisis que incluye varios niveles" (DAVIS, 2014, citado en LUZT, 2015, p.40). La inclusión es a juicio de Ocampo (2019) el principal pilar teórico de la investigación educativa.

Un política ontologica sugiere examinar exactamente la unidad de referencia común de nuestra especie (Braidotti, 2013), aparece como una alternativa en la teoría cultural y crítica del mundo actual. La comprensión del ser humano "actualmente está siendo reemplazado por una comprensión no dualista de la naturaleza interacción cultura" (BRAIDOTTI, 2013, p.3).

La inclusión en la que me intereso trabaja a favor de una compresión "epistemológica y moral que va más allá de las oposiciones binarias y atraviesa los diferentes polos del espectro político" (BRAIDOTTI, 2013, p.23).

La inclusión construye un ángulo específico de visión y, lo que es más importante, encarna un enfoque dinámico particular para las leyes subyacentes del movimiento de la realidad, crea nuevos diagramas de relacionamiento contingentes de posiciones y situaciones relacionales y transitivas que fomentan otras coordenadas de alteridad para acoger a la multiplicidad de singularidades. 


\begin{tabular}{|c|c|}
\hline $\begin{array}{l}\text { Dilemas } \\
\text { definitorios } \\
\text { fundamentales que } \\
\text { enfrenta }\end{array}$ & $\begin{array}{l}\text { Al pensar la educación inclusiva como objeto y campo de investigación, estrategia } \\
\text { analítica y praxis crítica, las configuraciones del territorio establecen que la 'inclusión' } \\
\text { como categoría de análisis enfrenta un problema definitorio particular, participa de las } \\
\text { relaciones de poder estructurales y de las representaciones culturales que interroga. }\end{array}$ \\
\hline $\begin{array}{l}\text { Especificidad de la } \\
\text { concepción } \\
\text { epistemológica de } \\
\text { la educación } \\
\text { inclusiva }\end{array}$ & $\begin{array}{l}\text { - } \quad \text { Epistemología de la dispersión. } \\
\text { - } \quad \text { Epistemología posicionada y neo-materialista. } \\
\text { - Actúa como un dispositivo macroeducativo o un sistema de recognición de la teoría } \\
\text { educativa contemporánea. } \\
\text { - Sus principales características son completamente aplicables a otros campos de } \\
\text { investigación. }\end{array}$ \\
\hline \multirow{24}{*}{$\begin{array}{l}\text { Características } \\
\text { epistemológicas } \\
\text { fundamentales }\end{array}$} & Diaspórico \\
\hline & Diversas convergencias heurísticas y lo post-disciplinar \\
\hline & Nomadista \\
\hline & Transposiciones \\
\hline & Malla de conexión reticular por redoblamiento \\
\hline & Traducción epistémica \\
\hline & Examen topológico \\
\hline & El carácter viajero \\
\hline & Las estrategias de rearticulación \\
\hline & $\begin{array}{l}\text { Las estrategias de construcción que atraviesan diversas convergencias y coyunturas } \\
\text { heurísticas }\end{array}$ \\
\hline & Micropolítica epistémica y analítica \\
\hline & Enredos genealógicos y sus trayectorias rizomáticas \\
\hline & El espacio de diáspora \\
\hline & El espacio migratorio \\
\hline & Proyecto de conocimiento en resistencia \\
\hline & Constelación heurística \\
\hline & Saber del presente \\
\hline & Movimiento \\
\hline & Pensamiento de la relación \\
\hline & Pensamiento del encuentro \\
\hline & Estructura teórica abierta \\
\hline & Heterotopicalidad \\
\hline & Zona de contacto \\
\hline & Ecología de saberes \\
\hline $\begin{array}{c}\text { La base } \\
\text { epistemológica }\end{array}$ & De naturaleza post-disciplinar \\
\hline \multirow{7}{*}{$\begin{array}{l}\text { Principios } \\
\text { epistemológicos } \\
\text { fundamentales }\end{array}$} & Principio de exterioridad \\
\hline & Principio de negatividad \\
\hline & Principio de edificación \\
\hline & Principio de ensamblaje \\
\hline & Principio de lo menor \\
\hline & Principio de recognición \\
\hline & Principio diasporismo \\
\hline \multirow{3}{*}{$\begin{array}{l}\text { Condiciones de } \\
\text { producción }\end{array}$} & $\begin{array}{l}\text { Condiciones generales de producción del conocimiento de la educación inclusiva: lo } \\
\text { post-disciplinar y la presencia de diversas clases de convergencias heurísticas que } \\
\text { ensamblan dicha trama de relaciones. }\end{array}$ \\
\hline & $\begin{array}{l}\text { Condiciones de producción intra-teóricas: lo nomadista, lo diaspórico, lo micropolítico, } \\
\text { los injertos, la traducción, el examen topológico, etc. }\end{array}$ \\
\hline & $\begin{array}{l}\text { Condiciones de producción extra-teóricas: diversas clases de tensiones sociopolíticas a } \\
\text { nivel estructural y microprácticos que impactan la vida de las personas. Se incluye en } \\
\text { este punto, la comprensión de diversas clases de problemas sociales, económicos y } \\
\text { políticos que regulan la red objetual del campo. }\end{array}$ \\
\hline $\begin{array}{l}\text { Orden de } \\
\text { producción o las } \\
\text { leyes internas del } \\
\text { campo }\end{array}$ & $\begin{array}{l}\text { Las leyes internas de funcionamiento del campo epistemológico de la educación } \\
\text { inclusiva acontecen a través del nomadismo, las transposiciones y el dasporismo. } \\
\text { Todas ellas, constituyen formas constructivas cruciales en la producción del } \\
\text { conocimiento del campo. }\end{array}$ \\
\hline
\end{tabular}

Tabla 4: Síntesis de las características epistemológicas de la educación inclusiva. Fuente: elaboración propia. 


\section{III.-La educación inclusiva es un espacio deslocalización, una singular forma de teorización diaspórica}

La educación inclusiva es el resultado de varias diásporas intelectuales, éticas, políticas, identitarias y metodológicas. Al ser la educación inclusiva un territorio en permanente movimiento, sus leyes constructivas operan en lo que Ocampo (2016) denomina: diáspora epistémica, es decir, un espacio de deslocalización de múltiples recursos constructivos inaugurando un campo aléctico. La teoría de la educación inclusiva es una teoría de la desubicación, es un campo de fenómenos dispersos por diversas latitudes heurísticometodológicas. No muestra centralidad exclusiva en ninguna de sus disciplinas y paradigmas, debido a su complejidad objetual, esta, los desborda. Sus tópicos de análisis, conceptos y herramientas analítico-metodológicas forman un singular figural, cada una de sus formas, a su modo, se encuentran esparcidas por diversas espacialidades intelectuales, forjando una singular malla de conexión que opera mediante la fuerza de la performatividad de lo rearticulatorio.

El espacio de producción epistemológico de la educación inclusiva al ser concebido como unidad relacional de deslocalización inaugura un singular territorio inexplorado atravesado por cruces y desbordamientos insospechados entre recursos constructivos de carácter cambiante y contextual, que se mueven entre formas de relocalización y dislocación. Uno de sus principales problemas describe la escasez de vocabulario disponible para asumir las problemáticas del campo en términos migratorio compuesto por "procesos de llegada y afincamiento en un lugar nuevo no solo engloban el presente y el futuro" (ANG-LYGATE, 2008, p.295). Las políticas de deslocalización desempeñan un papel relevante en la comprensión de los movimientos y giros que experimentan cada uno de los recursos constructivos que participan del ensamblaje de la educación inclusiva en tanto objeto y campo de investigación, no se encuentran fijas en los paradigmas de ninguna disciplina, tampoco saben a ciencia cierta a dónde pertenecen cada uno de sus conceptos, formas metodológicas, objetos circundantes, formas teóricas, entre otras. Cada uno de estos recursos constructivos muchas veces no es del todo comprendidos y aceptados por las formas dominantes y objetivistas de concebir el campo de fenómenos de lo inclusivo. Nos enfrentamos a articulaciones heurísticas de carácter deslocalizadas.

Si la educación inclusiva surge de diversos enredos genealógicos cuyas hebras se componen a través de la contribución del feminismo, los movimientos de la subalternidad, el antirracismo, la interculturalidad, entre otros proyectos políticos; cada uno, a su forma, representa un peso importante en la configuración de los contornos del campo, especialmente, en el diseño de una gramática ciudadana y política desconocida. A partir de estas raíces emerge 
la comprensión de lo inclusivo como proyecto político y diagrama de posiciones contingentes y transitivas cuya relacionalidad busca destrabar los sistemas de opresiones y dominaciones concebidas como injusticas que operan en todos los planos de la sociedad y de la vida psíquica y material. Un proyecto político y un diagrama de posiciones contingentes trabajan a favor de las tramas de regulación de la experiencia subjetiva y la experiencia colectiva. El problema que documenta gran parte del universo crítico-discursivo de la pedagogía de los sistemas de razonamientos de lo libertario es que estos son incapaces de alterar las estructuras de funcionamiento del poder instituido e imbricado en las reglas de funcionamiento institucionales de la sociedad y, por consiguiente, de las diversas modalidades del sistema educativo. Otra obstrucción que se desprende de tales argumentos describe que, la inclusión de la que más hablamos y conocemos se encuentra imbricada con los códigos de la política tradicional dando paso a un argumento liberal. La inclusión debe ser entendida como un sistema de (des)ensamblajes que rompen con cualquier forma de codificación reduccionistas; esta crea "nuevos diagramas contingentes de posiciones y situaciones relacionales y transitivas" (RICHARD, 2020, p.s/r.) que fomentan otras coordenadas de alteridad para acoger a la multiplicidad de singularidades, espacialidad que busca dar respuesta a través de la metáfora de 'vector proyectivo' de identidades y pasiones fracturadas, disconformes o devaluadas por las diversas capazes de la sociedad.

La diáspora en tanto categoría epistémica y analítica permite explorar los movimientos de cada uno de los recursos constructivos que participan del ensamblaje del campo denominado educación inclusiva, sus entendimientos complejos describen las modalidades de desplazamiento, migración, aterrizaje dislocación de diversas clases de singularidades epistemológicas. La diáspora posibilita entender las formas de movimiento inacabado, migración, reencuentro y transmigración que son establecidas específicamente a nivel heurístico, otorga herramientas para profundizar en el tipo de aleaciones, migraciones, forclusiones, injertos, interfaces, entre otras, a partir de cada uno de sus elementos confluyes, conformando un nuevo diagrama de recepción móvil -en adelante, campo de producción y campo de investigación- denominado por Ocampo (2017) espacio de producción diaspórica; un espacio habitado por múltiples recursos, inaugurando un singular campo aléctico. Una de las principales características de este espacio de producción epistemológica permite comprender las diversas formas de entrecruzamiento de sus genealógicas heurísticas devenidas en sistemas de enredos genealógicos que participan de la formación del campo. La educación inclusiva como disposición específica de verdad reconfigura la fuerza de lo múltiple. 
Al concebir el campo epistemológico de la educación inclusiva en términos de diáspora, es atravesado por diversas formas de desplazamientos, da cuenta de la participación de variadas clases de recursos analíticos y herramientas metodológicas, formas de migración de conceptos, métodos, sujetos, teorías, proyectos políticos y compromisos éticos que, si no logran ser rearticulados, corren el peligro de generar una figuración analítica por aplicación o agregación de elementos sin tocar la naturaleza de real de lo inclusivo. El espacio de diaspórica y la fuerza diaspórica de producción del conocimiento actúan mediante giros, desplazamientos, trayectorias rizomáticas, aleaciones por salto y redoblamiento, cruces insospechados que se encuentran a un desnivel teórico y metodológico sin precedentes. A través de la diáspora es posible examinar las diversas trayectorias de todos sus elementos constructivos atendiendo a sus diversas relaciones entre sus campos y múltiples sistemas de convergencias. Inaugura un juego heurístico de desterritorialización, performatividad de lo rearticulatorio y el giro por redoblamiento, desafiando las articulaciones de la política de localización de sus recursos convergentes desde el simple eclecticismo. Tanto la diáspora y las políticas de (des)localización a juicio de Brah (2011) poseen una sólida implicancia para entender las trayectorias, tácticas y movimientos de diversos campos, territorios y recursos heurísticos y metodológicos convergentes. Al concebir el campo de producción de la educación inclusiva como espacio de diáspora nos enfrenta a un territorio compuesto por múltiples modos de agenciamientos, un singular punto de confluencia de diversas cosas, un punto de mutación y agitación del pensamiento. El espacio de diáspora establece que la condición global heurística de la educación inclusiva queda definida como un lugar de complejas formas nomadistas, transposicones, traducciones, migraciones y viajes sin itinerarios fijos, inaugura un espacio habitado por recursos que han migrado y han sido rearticulados junto a sus descendientes o mutaciones, transitando por diversas convergencias heurísticas que enuncian y escuchan su campo de fenómenos en un singular y complejo más allá.

La condición diaspórica aplicada a la construcción del conocimiento de la educación inclusiva devela un efecto de dispersión que no es simplemente flotativa -esta condición es clave, es aquella que habilita el movimiento-, recurre a una forma que no actúa en términos de convergencia y centrismo, se encuentra en movimiento hacia múltiples direcciones. Es un campo de fenómenos que está siempre en vías de producción y siempre abierto al futuro. Es el resultado de la pluralidad, existencia de múltiples cosas que actúan a través de polifacéticas de trayectorias. Ocampo (2019) explica que existen diversas vías para acceder a la comprensión del dominio y objeto de la educación, trayectorias que operan en una singular modalidad rizomática, cuyos núcleos de configuración se mueven en diversos interfaces aproximándose a 
la comprensión de lo inclusivo hasta cierto punto, lo que exige de traducción epistémica. Cada una de estas rutas de acceso puede emprenderse desde cada uno de sus campos de confluencia, llegando a dialogar e interactuar con algunos objetos específicos del dominio. La inclusión es una diáspora compuesta por diversas cartografías de desplazamiento que explicitan un lugar central en la configuración de sus contornos. BRAH (2011) sostiene que, "no todos los viajes pueden considerarse diásporas. Las diásporas son claramente distintas de los viajes ocasionales. $\mathrm{Ni}$ tampoco se refieren a estancias cortas. Paradójicamente, los viajes diaspóricos buscan esencialmente establecerse, echar raíces «en alguna otra parte»” (p.213).

Si el orden de producción del campo acontece por vía del diasporismo y del nomadismo -leyes de funcionamiento de su orden de producción-, entonces, si estas categorías desean operar en términos de dispositivo heurístico enfrentaran la tarea de tener en cuenta la historia de las trayectorias de cada uno de sus recursos constructivos. Otra tarea consistirá en explicar en qué circunstancias y cómo estás se mueven. La diáspora reside en lo más profundo del principio de heterogénesis explicitando un campo ensamblado por múltiples diásporas específicas. En este punto nos enfrentamos a otro aspecto espinoso de comprender: cómo abordar y hacer legibles las diferencias y similitudes entre de una diáspora a otra. Al concebir los territorios de la educación inclusiva en términos de espacio de diáspora devela la presencia de una multiplicidad de entidades con sus propias trayectorias. Unidad relacional que se encuentra bajo construcción, un aparato reorganizativo, una simultaneidad espacial de diferencias, etc.

La comprensión de las formas constructivas de campo epistemológico de la educación inclusiva y sus tácticas de agenciamiento exigen atender a "las circunstancias de la partida, también lo son las de la llegada y el asentamiento" (BRAH, 2011, p.213) que acontecen al interior de una malla de relacionamientos heurísticos -múltiples posiciones relacionales- que alcanzan su esencia en el giro por redoblamiento continuo. Cada elemento se encuentra posicionado relacionalmente de forma multiaxial, demostrando una forma interna y una externa de la diáspora. La primera, alude a las relaciones de diferenciación entre ellas, mientras que, la segunda, examina las formas en que unas se sitúan en relación a otras. En la comprensión epistemológica de la educación inclusiva la gran red que alberga cada uno de los elementos que ensamblan sus contornos auténticos es denominado espacio de diáspora. A su vez, cada campo de confluencia forja diásporas específicas, estas pueden ser: el feminismo, la interseccionalidad, la filosofía de la diferencia, los estudios post-coloniales, los estudios de género, etc., múltiples ideas, premisas y argumentos que viajan y se movilizan incesantemente. La inclusión es de naturaleza viajera, a-centrada, no puede ser delimitada en los paradigmas de ninguna disciplina, 
pues, la fuerza del objeto desborda el vigor de toda figura conocida, operación cognitiva de naturaleza trasrelacional. El diasporismo epistemológico ayuda a transponer la naturaleza de cada uno de sus elementos.

\section{IV.-Conclusiones. La educación inclusiva surge de diversos enredos genealógicos y devela una trayectoria intelectual rizomática y desconocida}

Los enredos genealógicos constituyen un concepto central en la comprensión de los mecanismos de construcción del conocimiento de la educación inclusiva. Componen una sección significativa en la confluencia diversos proyectos de conocimiento en resistencia y proyectos políticos destinados a forjar un cambio social positivo. Los enredos genealógicos develan una fuerza analítica que emerge desde el concepto de espacio de diáspora (Brah, 2011) fomentando la visibilización de diversas genealogías que confluyen y ensamblan variadas comprensiones sobre algún punto de emergencia del dominio. La pregunta por los enredos genealógicos de diversos proyectos políticos y de conocimiento, junto a los múltiples elementos que forman sus agenciamientos da cuenta de diversas políticas de dispersión. Todo campo dinámico, inacabado, diaspórico y nomadista se encuentra atravesado y regulado por diversos enredos genealógicos, inaugurando un campo y un objeto en dispersión y en contradicción. Sus territorios pueden ser concebidos en términos de red de localización multiaxial de posiciones cuyo diagrama de análisis es concebido en términos de espacio de diáspora que funda su tarea “en una noción performativa multiaxial” (BRAH, 2011, p.275).

La inclusión en tanto fenómeno social, cultural y político surge de varios proyectos políticos comunes estructurados sobre la base de supuestos teóricos, éticos y metodológicos transversales y desconocidos. Sus territorios son el resultado del agenciamiento de diversos proyectos políticos destinados a la creación de otros mundos. La heterogeneidad y la heterogénesis son dos de sus epítetos de mayor preeminencia, cuyos territorios y ensamblajes explicitan un engranaje que asume "un devenir que siempre está en proceso de adaptarse, transformarse y modificarse en relación con su entorno" (GUATTARI, 1992, p.96). La heterogénesis no debe ser confundida con la supremacía de las políticas de todo vale o la diversificación de su contenido que impone una táctica de relativismo propia de los campos abiertos. Bajo ningún punto de vista, puede ser descrita su naturaleza, alcance y función en términos de una simple constelación de teorías, conceptos, proyectos intelectuales, éticos y políticos con cierto grado de intereses y preocupaciones comunes. A pesar de estas tensionalidades, fomenta la emergencia de nuevos modos de investigación. La inclusión es hoy una categoría heurística en estado latente. 
La educación inclusiva como campo de problemas contingentes, políticos, relacionales, transitivos y atentos a las tácticas oblicuas de la multiplicidad de singularidades, se propone "avanzar en una perspectiva crítica en la que tanto la discursividad como la materialidad (en otras palabras, prácticas discursivas y fenómenos materiales) puede ser integrado en un enfoque relacional" (OPPERMANN, 2011, p.155). Al constituir un proyecto de conocimiento en resistencia que surge de la interacción de diversas clases de enredos genealógicos y hebras que poseen la capacidad de entrelazar mediante la performatividad de lo rearticulatorio diversos objetos, acciones y movimientos, inaugura un campo de referencia diferencial. Los enredos genealógicos constituyen un concepto fundamental en la comprensión epistemológica de la educación inclusiva demostrando la presencia de un campo policéntrico con múltiples diásporas y micro-diásporas operando sobre perspectivas cambiantes, no identificadas e intensamente contingentes.

La fuerza expansiva de los objetos específicos que componen el gran campo de problemas de la educación inclusiva describen una trayectoria rizomática y multidireccional inaugurando un territorio de apertura ambivalente y una estructura abierta -signo de una fuerza epistemológica inacabada-, compuesto por límites y contornos difusos, turbios y opacos. Cada uno de estos epítetos no debe entenderse literalmente, pues su fuerza teórica y política denota un compromiso con muchos frentes que no siempre pueden ser bien definidos. Hasta aquí, en su estructura queda integrada por una diversidad de voces que contribuyen a la comprensión de variados tópicos y vínculos con las diversas estructuras del mundo y sus sistemas, exigiendo la adopción de nuevos métodos para problemas que no logran ser comprendidos bajo el purismo conservador del trabajo metodológico.

La ausencia de metodología para OPPERMANN (2010) no es otra cosa que la "falta de debate interno radical" (p.18), inaugura una naturaleza de multifacética, poliédrica y multiestratificada regulada por los principios de "conexión, heterogeneidad, multiplicidad y ruptura asignificante" (DELEUZE \& GUATTARI, 1970, p.79). Todas ellas, en su mayoría categorías cruciales del discurso postmoderno.

Al construir un diagrama de multiplicidades heurístico-políticas su redefinición ontológica evita ser atrapada por el esencialismo y sus clásicos sistemas de binarismos, entraña el deseo de ecologizar las diversas clases de objetos y discursos que participan de su ensamblaje reafirmando su compromiso con una naturaleza atravesada por el principio de heterogénesis, describiendo que la orgánica del campo se encuentra en permanente adaptación, alteración, transformación y creación. 


\section{REFERENCIAS}

ANG-LYGATE, Magdalene. (2008). “Trazar los espacios de deslocalización. De la teorización a la diáspora", en: FABARDO, Mercedes. (Edit.). Feminismos negros. Una antología. (pp.291-314). Madrid: Traficantes de Sueños.

ANTHIAS, Floya. (1998). Rethinking Social Divisions: Some Notes Towards a Theoretical Framework. Sociological Review, 46(3), 505-535.

BRAH, Avtar. (2011). Cartografías de la diáspora. Identidades en cuestión. Madrid: Traficantes de Sueños.

BRAIDOTTI, Rosi. (2009). Transposiciones. Barcelona: Gedisa.

BRAIDOTTI, Rosi. (2013). Feminismo, diferencia sexual y subjetividad nómade. Barcelona: Gedisa.

BRAIDOTTI, Rosi. (2020). Sujetos nómades. Buenos Aires: Paidós.

CULLER, Jonathan. (2009). Structuralist Poetics. Structuralism, linguistics and the study of literature. London: Routledge \& Kegan Pau.

DAVIS, Kathy. (2014). "Intersectionality as a Critical Mathodology"; en: LYKKE, N. (Ed.) Writing Academic Texts Differently: Intersectional Feminist Methodologies and the Playful Art of Writing. (pp. 268-281). New York: Routledge.

GONZÁLEZ, Brais. (2018). La ética diferencial de Rosi Braidotti. Agora. Papeles de filosofia, 37(2), 173-191.

DELEUZE, G. \& GUATTARI, F. (1970). La lógica de sentido. Barcelona: Edit. Six Barral.

GUATTARI, Félix. (1992). Las tres ecologías. México: FCE.

KYROLE, Katarina, KOIVUNEN, Anu \& RYBERG, Ingrid. (2019). Vulnerability as political language. Recuperado el 24 de junio de 2020: https://www.manchesteropenhive.com/view/9781526133113/9781526133113.00005.x $\mathrm{ml}$

LUZT, Helma. (2001). Intersectionality as. DiGeSt. Journal of Diversity and Gender Studies, Vol. 2, No. 1-2 (2015), pp. 39-44.

MASSEY, Doreen (1994). Space, Place and Gender. London: Routledge

OCAMPO, Aldo. (2016). "Gramática de la Educación Inclusiva: ejes críticos para cartografiar sus condiciones de producción y funcionamiento epistémico", en: Ocampo, A. (Comp.). Ideología, discapacidad y dominación: los imaginarios constitutivos de la discapacidad en Latinoamérica. (73-159 pp.). Santiago: Fondo Editorial CELEI.

OCAMPO, Aldo. (2017). Epistemología de la educación inclusiva. Granada: UGR.

OCAMPO, Aldo. (2019). Contornos teóricos de la educación inclusiva. Revista Boletín Redipe, Vol. 8 (3), 66-95.

OCAMPO, Aldo. (2020). En torno al verbo incluir: performatividades heurísticas de la educación inclusiva. Quaest.disput, 13 (27), 18-54.

OPPERMANN, Serpil. (2010). The rhizomatic trajectory of ecocriticism. Recuperado el 27 de noviembre de 2020 de: https://ecozona.eu/article/view/314

OPPERMANN, Serpil. (2011). Ecocriticism's Theoretical Discontents. Recuperado el 25 de marzo de 2020

de:

https://www.researchgate.net/publication/236830201_Ecocriticism's_Theoretical_Discontents RICHARD, Nelly. (2020). De la revuelta social a la nueva constitución en Chile. Conferencia leída el 16 de diciembre de 2020 en el Centro Cultural Kirchner. Recuperado el día 28 de diciembre de 2020 de: https://www.youtube.com/watch?v=pIl8SJEW9Hw 


\section{SOBRE O AUTOR}

\section{Aldo Ocampo González}

Doctor en Ciencias de la Educación, aprobado Sobresaliente mención 'Cum Laude' por unanimidad por la Universidad de Granada, España. Teórico y ensayista educativo. Director fundador del Centro de Estudios Latinoamericanos de Educación Inclusiva (CELEI), Chile. Correio eletrônico: aldo.ocampo@celei.cl

(iD) https://orcid.org/0000-0002-6654-8269 